International Journal of

Health, Medicine and

Nursing Practice

(IJHMNP)

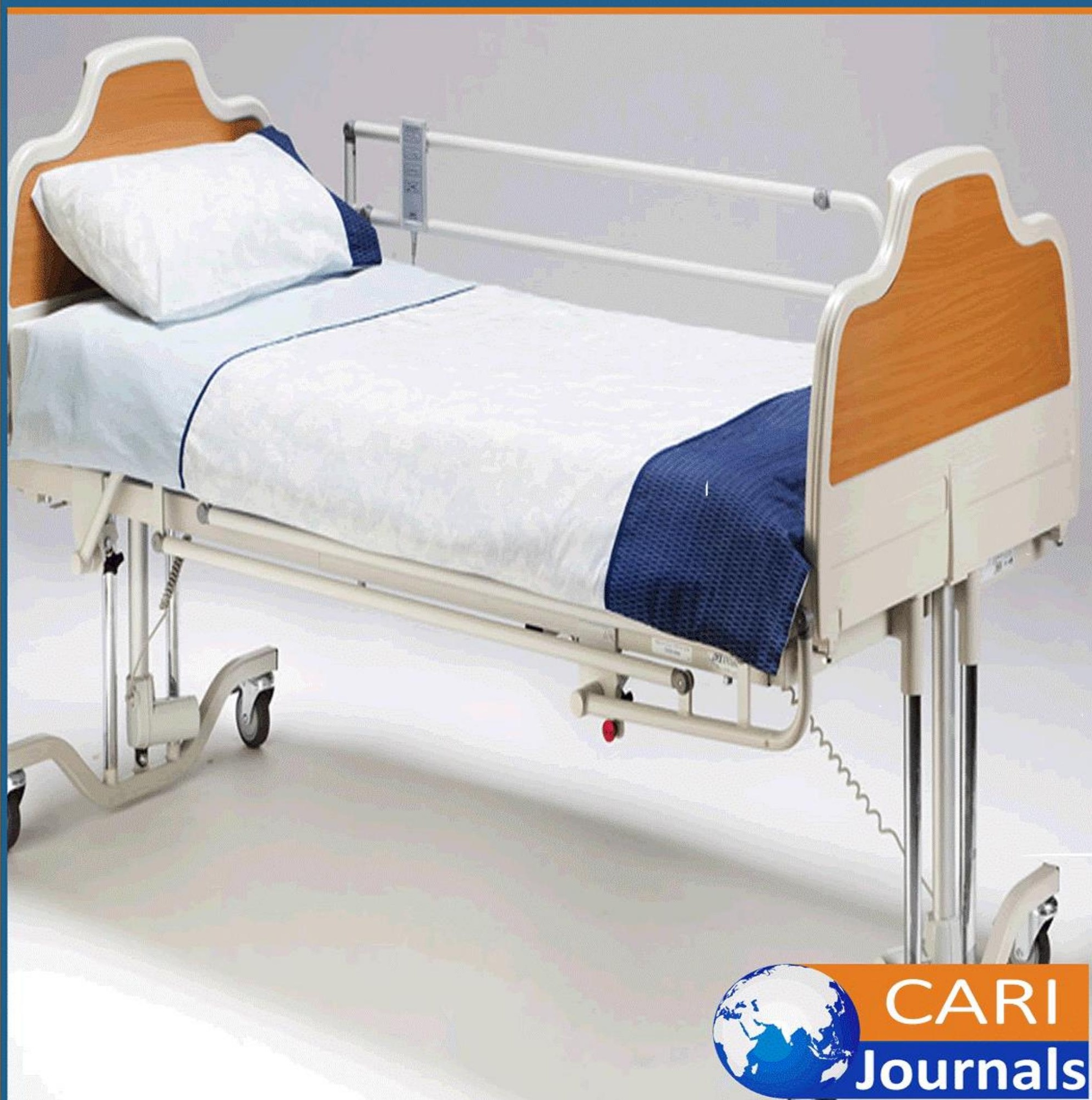




\title{
Assessment of Knowledge, Attitude, and Practices of Nurses towards Pharmacovigilance and Adverse Drugs Reactions Monitoring and Reporting: Cross-Sectional Study in Lahore, Pakistan
}

$1 *$ Maliha Shoukat

BSN (Post RN), Lahore School of Nursing, The University of Lahore

*Corresponding Author E-mail: maliha9969@gmail.com

${ }^{2}$ Muhammad Hussain

Associate professor Lahore School of Nursing, The University of Lahore, PhD Scholar,_Master of Science in Nursing

${ }^{3}$ Kousar Perveen

Assistant Professor, Lahore School of Nursing, The University of Lahore, Master of Science in Nursing

${ }^{4}$ Muhammad Afzal

Principal, Lahore School of Nursing, The University of Lahore, Master of Science in Nursing

${ }^{5}$ Muhammad Saghir

BSN (Post RN), Lahore School of Nursing, The University of Lahore

\begin{abstract}
Purpose: The purpose of the study is to determine nurses' current knowledge, attitudes and practices towards pharmacovigilance and adverse drug reactions monitoring and reporting.

Methodology: A cross-sectional study was conducted. The target population 154 nurses who work in Tertiary Care Hospital, Lahore, Pakistan. The sample size was calculated by the "World Health Organization" online sample size calculator. A well-structured questionnaire on adverse drug reactions reporting was used for data collection. The data was analysed by using SPSS version 25 . The Pearson correlation test used to assess the relationship between knowledge, attitudes, and practices regarding adverse drug reactions. Pearson correlation at $\mathrm{p}<0.05$ consider as significant. The study results display in tables and charts.

Findings: The study was carried out to assess the knowledge, attitude, and practice towards Pharmacovigilance and adverse drug reactions and reporting. 56.5\% of nurses had a concept of pharmacovigilance. The $39.6 \%$ know the voluntary reporting system of adverse drug reaction. Only 36.4\% nurses responded agree for policies and procedures should be developed for monitoring and reporting of adverse drug reaction.
\end{abstract}

Unique Contribution To Theory, Practice And Policy: This study is a way of improving pharmacovigilance programs in the country, public awareness on reporting. This could be done to 
International Journal of Health, Medicine and Nursing Practice ISSN 2710-1150 (Online)

Vol. 3, Issue No. 1, pp 24- 43, 2021

$\underline{\text { www.carijournals.org }}$

improve practice by advertising and encouraging patients to self-reporting to their nearest health facility. Public awareness could be done through social media. The responsible regulatory authority, with assistance from other relevant stakeholders, should design the reporting forms and make them easily available and accessible so that the public may use them for reporting adverse drug reaction.

Keywords: Knowledge, Attitude, Practices, Nurses, Adverse Drug Reactions, Pharmacovigilance

\section{INTRODUCTION}

Medicine is an important innovation that improves the quality of life of people with diseases. Although efficacy and potency have been described as important properties of the drug. It can also have the ability to produce some reactions that are undesirable and are called drug adverse reactions. Unpleasant drug reactions are adverse drug reactions that result from the use of medical products (Napuce \& Tabaku, 2019). Drug-to-drug interaction is harmful and the leading cause of illness and death. With an ageing population, an increase in pharmacovigilance, widespread use of supplements, and a growing epidemic of opioid abuse, primary care physician are increasingly challenged to identify and prevent drug-to-drug interactions that are going. We set out to review existing clinical approaches to the identification and treatment of Drug-to-drug interactions and to determine if opportunities can be identified to increase the prevention of Drug-to-drug interactions and their adverse events (Peabody et al., 2018). It depends heavily on the patient's sensitivity to the drug and the combination of medications used. It does not usually cause severe drug reactions but is relatively common. Allergic drug reactions occur when patients develop an inappropriate reaction to the medication, which can be largely avoided through effective consultation and interaction between primary care facilities and patients, or skin tests. A side effect is a type of adverse drug reaction that is not widely understood and is often unpredictable. Very few people are affected and the cause of the adverse reaction may be genetically predetermined(Khalil \& Huang, 2020).

To monitor the known and unknown adverse effects of medications, the process of self-reporting is very important. Automatic reporting of adverse drug reactions from medical trials, postmarketing surveillance, and healthcare professionals is important. In addition, it can play an important role in detecting lethal and new adverse drug reactions during drug marketing in actual practice in the market. This exercise has resulted in a very successful withdrawal of many drugs in the past, such as cisapride, Rofecoxib, terfenadine, etc (Kumari et al., 2020). Under current regulations, it is the responsibility of all healthcare professionals (medical doctors, dentists, nurses, pharmacists, and midwives) to ensure all adverse reactions to drugs. The drug reactions of the accused should be observed and reported.(RM, Kalpana, \& CR, 2021).

Nurses, in their unique ability to record observational effects of drug use as drug administrators, have been instrumental in reporting adverse drug reactions and have been able to independently report adverse drug reactions in hospitals. Reports is a valuable contributor. Create resources, as they are close to patients and have a good knowledge of the patient's health status, symptoms, drugs and drug reactions. They are often a means of alerting the printer responsible for possible drug reactions. There is a logical reason to involve nurses and encourage them to participate in 
International Journal of Health, Medicine and Nursing Practice ISSN 2710-1150 (Online)

Vol. 3, Issue No. 1, pp 24- 43, 2021

$\underline{\text { www.carijournals.org }}$

drug adverse reporting systems (Hanafi et al., 2012). Reporting adverse drug reactions is important for establishing health standards. Furthermore, medical knowledge is not only important for pharmacists, but also increases the training and awareness of healthcare workers in reporting drug reactions and adverse drug reactions.(Adenuga, Kibuule, Rennie, pharmacology, \& toxicology, 2020).

The biggest ban on Pharmacovigilance is the low number of reports of adverse drug reactions from nurses in hospitals. Pharmacovigilance are an integral part of healthcare aimed at improving patient safety. The primary responsibility of a nurse is to report any adverse drug reactions and to strengthen the Pharmacovigilance program in the country.(O'Callaghan, Griffin, Morris, \& Bermingham, 2018). The Punjab government is the first provincial government to set up a provincial office of the Directorate General of Health Services, Pharmacovigilance Center in Punjab.(Hussain, Hassali, Hashmi, Farooqui, \& practice, 2018). The Provincial Drug Control Unit Punjab is formulating policies and procedures on aspects related to drug control. A total of $91 \mathrm{drug}$ safety warnings have been issued since its operation. Despite the fact that the data is updated on a regular basis, there is a gap in communication between drug regulatory authorities and healthcare professionals (Hussain et al., 2018).

Knowledge, attitude, and Practice Surveys are representative of a specific population that collect data about what is known, believed and Practiced in relation to a specific topic, and is one of the most widely used studies in health behavior research(Garg, Sharma, \& Bajaj, 2017). Knowledge is generally assessed to determine how well the community's knowledge compares to biomedical concepts. Behavior is defined as "the learned danger of thinking, feeling, and acting in a certain way toward a particular object or class of objects." Similarly, behavior is the result of a complex interaction of beliefs, feelings and values. Exercises usually ask about tive precautions or the use of different healthcare options.(Adisa \& Omitogun, 2019).

Nurses are usually posted in hospital settings, for nursing care of the patienst. Pakistan stands in those countries where the ratio of nurses to doctors is $1: 2.7$ and this poor ratio greatly compromises the role of nurses in healthcare settings. In Pakistan, a nurse in a hospital is responsible for the distribution of medicines, compliance with doctors' orders and other administrative tasks.(Hussain et al., 2018). Thus, the purpose of the present study was to describe nurses' knowledge, attitudes, and practice of monitoring and reporting adverse drug reactions. This can help identify the current need for Pharmacovigilance education / training and research to improve the knowledge, attitudes, and our understanding of Pharmacovigilance and drug reactions to healthcare workers and students.

\section{Significance of the Study}

This study could provide healthcare policy makers and planners with information on the current state of reporting drug reactions among healthcare professionals especially nurses. It will provide information that could be used to rehabilitate or rebuild public health pharmacovigilance in the future. The study is the first of its kind to assess factors affecting nurses' reporting of adverse drug reactions. It will provide suggestions for improving reporting by nurses. The study provides stakeholders with information on the current state of reporting drug adverse reactions and thus 
enables them to discuss appropriate procedures to improve the reporting process. This will determine the actual interventions needed to improve the reporting of adverse reactions, which could identify potential factors that could lead to underportation. Information on reporting adverse drug reactions such as knowledge, awareness and action and barriers need to be reviewed and needs related to these factors identified. This will provide valuable data on pharmaceutical and drug adverse drug reporting issues that can be used to improve and advance the pharmacological system.

\section{Statement of the Problem}

The concept of pharmacovigilance has become more important worldwide due to an increase in the number of drug molecules entering the market and most countries have since established pharmacovigilance centres. In 2003, Pakistan's national drug policy called for the establishment of a drug surveillance and surveillance system. An estimated $6.7 \%$ of hospitalized patients have a serious drug reactions. If these estimates are correct, then hospitalized patients have more than 2,216,000 severe drug reactions, resulting in more than 106,000 deaths each year (Atif et al., 2020). It is not possible to experience adverse drug reactions but this is a problem of not reporting. Considering that nurses are responsible for intimate care and medication administration. Managing and reporting adverse drug reactions becomes an important responsibility for them. Therefore, from this study, to assess the knowledge, attitude and practice of nurses regarding reporting adverse drug reactions and to determine the difference in knowledge, attitude and practice among nurses at Tertiary Care Hospital, Lahore.

\section{Objective of the study}

The objective of the study was to assess nurses' current knowledge, attitudes, and practices regarding pharmacovigilance and drug reactions monitoring and reporting at Tertiary Care Hospital, Lahore.

\section{Operational Definitions}

\section{Adverse Drug Reaction}

A harmful or unpleasant reaction resulting from an intervention related to the use of a medicinal product.

\section{Pharmacovigilance}

It is the pharmacological science relating to the assessment, detection, collection, monitoring, and prevention of adverse effects with pharmaceutical products.

\section{Knowledge of Pharmacovigilance and Adverse Drug Reaction}

The Knowledge of nurses is measured by Questionnaire toward pharmacovigilance and adverse drug reaction.

\section{Attitude of Pharmacovigilance and Adverse Drug Reaction}

It indicates the belief of nurses toward pharmacovigilance and adverse drug reaction. 
International Journal of Health, Medicine and Nursing Practice

ISSN 2710-1150 (Online)

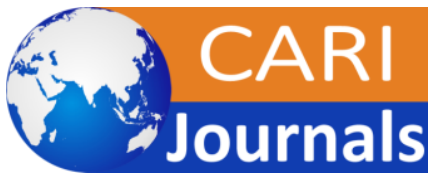

Vol. 3, Issue No. 1, pp 24- 43, 2021

www.carijournals.org

\section{Practice of Pharmacovigilance and Adverse Drug Reaction}

It referred to the level of nurses' ability or skill practice to identify adverse drug reaction.

\section{Research Hypothesis}

\section{Null Hypothesis}

$>$ They have no knowledge, attitude, and practice regarding pharmacovigilance and adverse drug reaction monitoring and reporting at Tertiary Care Hospital, Lahore.

\section{Alternative Hypothesis}

$>$ They have the knowledge, attitude, and practice regarding pharmacovigilance and adverse drug reaction monitoring and reporting at Tertiary Care Hospital, Lahore.

\section{LITERATURE REVIEW}

\section{Theoretical Review}

\section{Figure \#01 Managing Adverse Drug Reactions: an 'Orphan Task'}

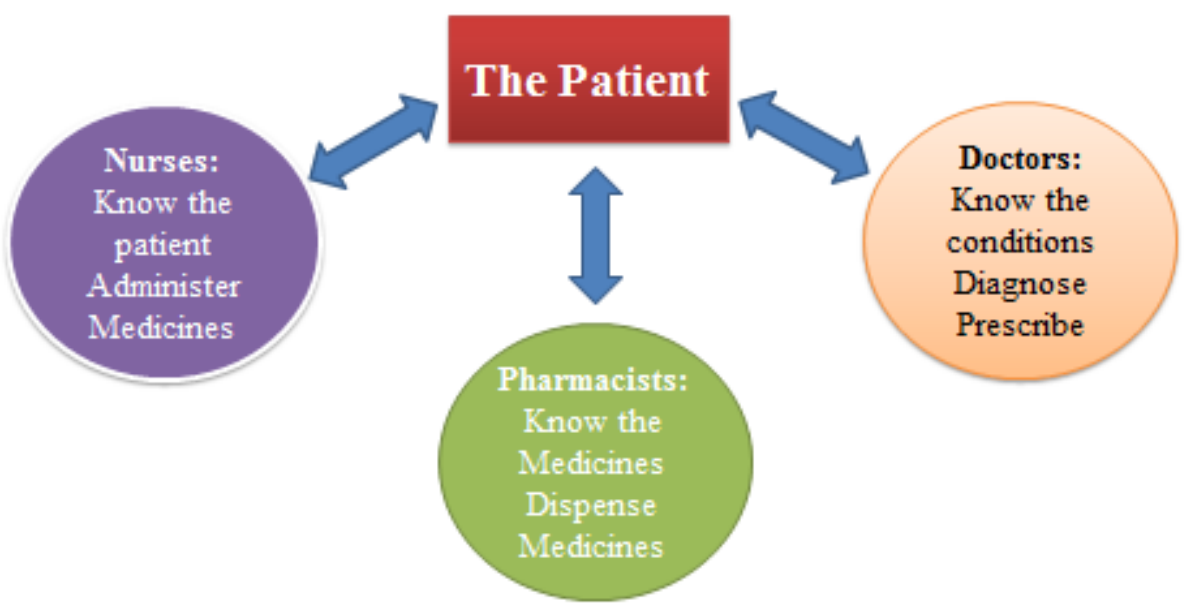

(Figure \#01) shows that traditionally, doctors prescribe, pharmacists send, and nurses administer medicine. Although the role of some nurses and pharmacists has been enhanced, monitoring patients with potential drug reactions is not a given to single profession. It is important to report drug reactions to protect patients. Inadequate attention has been paid to the identification of adverse drug reactions and no appropriate global approach has been adopted and implemented in clinical practice to monitor and manage adverse drug reactions (Susan Jordan et al., 2015). 
International Journal of Health, Medicine and Nursing Practice

ISSN 2710-1150 (Online)

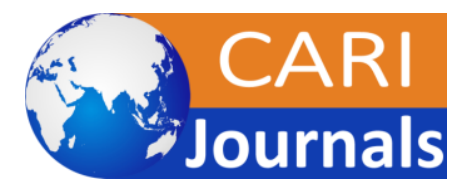

Vol. 3, Issue No. 1, pp 24- 43, 2021

Www.carijournals.org

\section{Empirical Review}

Medications with useful effects also have side effects that can have side effects on patients. Therefore, awareness of adverse drug reactions among medical workers is an essential component of a well-established organization.(Coleman \& Pontefract, 2016). Pharmacovigilance has been described as a global science and science activity related to the identification, diagnosis, and prevention of adverse drug reactions. Pharmacovigilance plays an important role in the study of drug safety. Pharmacovigilance is a multidisciplinary field for detecting, diagnosing, understanding and preventing drug reactions. About $95 \%$ of drug reactions are undocumented. However, due to lack of resources, infrastructure and expertise, developing countries lack information on the burden of drug adverse reactions (BR \& Kar, 2020). Adverse drug reactions are unannounced drug reactions. It has also been described as a reaction to a drug that would be harmful and unintentional, and in the amount that is commonly used in humans for prophylaxis, therapy, diagnosis, or modification of bodily functions. Is practiced Awareness of adverse drug reactions in the pharmaceutical process, which can be described as the science of detecting, understanding, diagnosing and preventing adverse effects or any potential drug-related problems.(Elhassan, 2015). To reduce the risk of drug adverse reactions, we have a branch of Pharmacovigilance called science and activities related to prevention, diagnosis, understanding and prevention of any possible risk of side effects realted to drugs issues including herbal ingredients (Zaman et al., 2021).

Numerous studies to assess knowledge, attitude and practice in nurses have documented that nurses have a lack of knowledge that how to report adverse drug reactions.(John, Arifulla, Cheriathu, \& Sreedharan, 2012). Adverse drug reactions are the leading cause of illness and death worldwide. The literature suggests that $6 \%$ of hospital admissions can be attributed to adverse drug reactions. Worldwide, adverse drug reaction cases cause an emergency hospitalization with a difference of 0.2 to $41.3 \%$, while $28.9 \%$ of these adverse drug reactions are treatable. In 2012, a meta-analysis found that $52 \%$ of adverse drug reaction -related emergency hospital admissions and $45 \%$ of patients with adverse drug reactions could be prevented (Bhagavathula, Elnour, Jamshed, \& Shehab, 2016). Healthcare workers play an important role in the pharmaceutical system, and thus provide them with sufficient information in the field of drug safety, especially for early identification, detection, administration and reporting of adverse drug reactions.(Almandil, 2016). Furthermore, studies have indicated that a large numbers of adverse drug reactions are not reported by healthcare workers, especially in developing countries. Due to multiple factors, including the reporting and pharmacovigilance which indicates a lack of awareness.(Adisa \& Omitogun, 2019).

Nurses' leadership is an important strategy to reduce the problems associated with patient drug reactions. Monitoring and reporting system of drug response do not replace medical knowledge and experience, but they combine information on drug reactions signs and symptoms, informal diagnosis and compliance guidelines so that the proposed Suggest solutions to drug problems.(Susan Jordan et al., 2015). An analysis of the Italian Pharmaceutical Database shows that in the years 2004-202010, with only 1951 reports (approximately 2.6\%) from nurses, 74657 adverse drug reactions were received from different types of reporters. Nevertheless, Italian nurses 
International Journal of Health, Medicine and Nursing Practice ISSN 2710-1150 (Online)

Vol. 3, Issue No. 1, pp 24- 43, 2021

$\underline{\text { www.carijournals.org }}$

are expected to report adverse drug reaction through the Pharmacovigilance Italian system since 2003. The reasons for under-reporting in Italian nurses have not been fully investigated and only one Italian study has described the hospital's nurse staff's lack of expertise in detecting adverse drug reactions. According to the authors, this result is probably due to a lack of information on pharmacology and adverse drug reaction (De Angelis, Giusti, Colaceci, Vellone, \& Alvaro, 2015). Negative impacts on patient health, and the burden of incident data records on the healthcare system, effective policies and strategies are needed to meet the challenge of adverse drug reactions. Policy-making has been instrumental in providing nurses with safe pharmaceuticals, healthcare reform, and improving nursing practice. (Sue Jordan, Vaismoradi, \& Griffiths, 2016).

Awareness of the negative effects of drugs arose in the 18th century through the formation of a chain or cluster that resulted from the use of certain drugs.( sulfonamide disaster, thalidomide disaster, etc.) (Garg et al., 2017). After which more and more attention is being paid so far which has resulted in the emergence of a new science called pharmacovigilance.(Nisa, Zafar, \& Sher, 2018). The major source of information in pharmacovigilance being voluntary adverse drug reaction reporting system (Sen et al., 2017). A review of the Pharmacovigilance system help to identify its shortcomings and take steps to improve the quantity and quality of drug adverse reactions reports and other opportunities to strengthen the Pharmacovigilance system.(Khalili et al., 2020). Many of the factors that affect the presence of adverse drug reactions can be summarized as dose, timing, and sensitivity, which reflect the drug, the reaction, and the characteristics of the patient. Factors that change the individual's sensitivity include genetic immunological factors, sex, age, physical changes, external effects and disease conditions. The interactions between these factors help explain why some patients experience severe adverse reactions while others are not affected. And it all depends on the amount of drugs (Ferner \& Aronson, 2019). The importance of Pharmacovigilance is safety and monitoring of medicinal products, pharmaceutical monitoring, drug preparations, adverse effects, reporting of adverse drug reactions, product monitoring, post-marketing and legislation.(Nasir, Zahan, Farha, Chowdhury, \& Pharmacology, 2020). Inadequate monitoring of adverse reaction affects more patients. Drug reactions monitoring and reporting programs identify and minimize adverse drug reactions while helping nurses deal with drug reactions effectively.

The relatively recent development, the inclusion of nurses in Pharmacovigilance programs could significantly increase the number of reports. Among healthcare professionals, because of their unique role in assisting nurses' patients and educating patients, by making treatment arrangements and reporting signs and symptoms of adverse drug reactions. As such, they often have a special role to play with the patient. It is estimated that more than 350,000 drug reactions occur in nursing homes in the United States each year.(Bigi \& Bocci, 2017). Preventing the onset of adverse drug reactions should be considered one of the specific goals of healthcare workers, and especially for community and clinical health nurses, who are committed with health of patients and the community as a whole are fundamental to safety, with extra focus. More vulnerable subjects, such as elderly and children. In fact, the role of nurse in community goes beyond simple care of patients in society and includes the promotion and prevention of community health through health education programs, community-level organization and community reform.(Sue Jordan et al., 2016). 
Nurses play a key role in Pharmacovigilance activities, especially in identifying drug adverse reactions that are beyond the reach of other health care providers and are fundamental to protecting the health of patients and the community as a whole. Status, as much attention is paid to vulnerable patients such as elderly and children.(Bigi \& Bocci, 2017). Better medication monitoring can prevent many drug reactions. Healthcare systems require nurses to take professional responsibility for the maximum management of drug adverse reactions so that they can identify and explain problems and get the attention of prescribers. Bring in The most adverse drug reactions are preventable, but they depend on the attitudes, knowledge and skills of health care providers, and timely identification and reporting. These barriers will be overcome through formal co-operation in safety measures and nursing leadership.(Garg et al., 2017). Nurse administrators and policymakers have the opportunity to develop, apply and mandate structured medication monitoring systems. However, rates of drug adverse reactions reported by healthcare professionals are still low. Limitations and delay measures that can be taken to minimize the risk of serious adverse effects of medications. Nurses among healthcare professionals are known to play an important role in reporting drug adverse reactions and they form a valuable tool for reporting drug adverse reactions in hospitals. Thus, the opinions and attitudes of hospital nurses on the troubles of spontaneous reporting of adverse drug reaction and the ways to resolve them are very important (RM et al., 2021).

\section{Research Gap}

What knowledge do nurses have on pharmacovigilance?

What do nurses think of adverse drug reactions reporting?

What do nurses do when an adverse event has occurred?

Are there any differences in knowledge, attitude and practice among the nurses?

\section{METHODOLOGY}

Study Design: A cross-sectional study was conducted.

Settings: Tertiary Care Hospital, Lahore

Duration of Study: From February 2021 to May 2021

Sample Size: Sample size 154 that was calculated by the "World Health Organization" online sample size calculator. Expected confidence level 95\%, absolute accuracy 0.06, projected population ratio 0.826 . Sixteen added to the sample size $(n=154)$ to overcome non-response and failure to follow-up.

\section{$\mathbf{n}=\underline{\mathbf{z}^{2}} \mathrm{a} / 2 \mathbf{p}(\mathbf{1 - p})$ \\ $\mathbf{d}^{2}$}

$\mathbf{Z}_{\mathbf{a} / \mathbf{2}}$ Divide the confidence interval by two, and look that area up in the z-table:

$0.95 / 2=0.475$

the closest z-score for 0.475 is 1.96 . 


$$
\begin{aligned}
\mathrm{p} & =0.826 \\
\mathrm{~d} & =0.06 \\
\mathrm{n} & =\frac{(1.96)^{2} \times 0.826(1-0.826)}{(0.06)^{2}} \\
\mathrm{n} & =\frac{3.8416 \times 0.826 \times 0.174}{0.0036} \\
\mathbf{n} & =\mathbf{1 5 4}
\end{aligned}
$$

\section{Sampling Technique}

Simple random sampling methods were used to collect data.

\section{Inclusion Criteria}

The inclusion criteria include all the bed sided nurses who work in selected Tertiary Care Hospital, Lahore.

\section{Exclusion Criteria}

All nurses who were not directly involved in patient management (Nursing supervisor, Head nurses, on annual leave, sick leave, and other health workers) were not included in the study.

\section{Data Collection Procedure}

Data were collected through a structured questionnaire. The consent was sign by the participants before filling out the questionnaire. The questionnaire used in this study was derived from Hashmi et al., 2020. A questionnaire was given to the nurses who agreed to participate. The researcher asked participants to complete the questionnaire at the same time so that they could not use the internet and other resources to answer the questions. The researcher's interventions were applied to explain the difficulties faced by the participant in understanding the applicants' questions.

The final questionnaire consists of five sections, including demographic information, knowledge towards adverse drug reaction and Pharmacovigilance, attitudes and practices regarding adverse drug reaction reporting, respectively. The level of knowledge regarding pharmacovigilance was determined using a series of 6 questions, the level of knowledge regarding adverse drug reaction was assessed by 5 questions, what they were, reporting structures, who to report to and how to report. The attitude towards adverse drug reaction reporting was assessed using 9 statements, including reasons for not reporting or under-reporting. The respondent's practice towards adverse drug reaction reporting was examined using 10 questions, if there is a reporting system in their institution, if they have experienced a drug adverse reaction to a patient and if they have you ever reported a negative event?

\section{Study Variables}


International Journal of Health, Medicine and Nursing Practice ISSN 2710-1150 (Online)

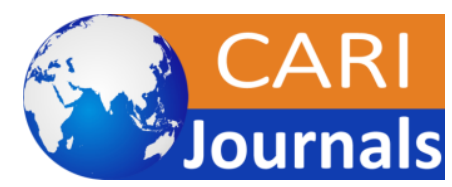

Vol. 3, Issue No. 1, pp 24- 43, 2021

Www.carijournals.org

Knowledge, Attitude, and Practices of nurses towards pharmacovigilance and adverse drug reactions.

Age and Sex of respondents

Education level, Marital status and Monthly incomes

Training regarding pharmacovigilance and adverse drug reaction

\section{Data Analysis Procedure}

The data was analyzed by using (SPSS) statistical packages for social sciences version 25 . The questionnaires were given identification numbers and the questions were coded. Collected data collected were entered in Microsoft Office Excel (2010). Descriptive statistics were used to calculate the percentage and frequencies. Pearson correlation test was used to determine the correlation between the knowledge, attitude and practice of pharmacovigilance and adverse drug reaction reporting among the categories of nurses at a significance level of $<0.05$. Data were summarized using frequency tables and charts.

\section{FINDINGS AND PRESENTATION}

\section{Socio-Demographic Characteristics}

A total of 154 female nurses were approached. The mean age was 21-30 which shows that $81(52.6 \%)$ nurses were between this age group. Only $9(5.8 \%)$ nurse's age group above 50years. Most of the participants were diploma holder 100(64.9\%) and only 54(35.1\%) specialized. The $125(81.2 \%)$ out of 154 had $1-5$ years experience and only $29(18.8 \%)$ had more than 5 years experience in their field. The annual income of participants falls in the medium category $128(83.1 \%)$ and only 26(16.9\%) participants had high-income status. Most of the participants about $129(83.8 \%)$ don't have any training 25(16.2) participants trained regarding Adverse drug reaction or Pharmacovigilance (Table \#01).

Table 1: Socio-Demographic Characteristics of Study Participants

\begin{tabular}{lllcc}
\hline S/No & \multicolumn{1}{c}{ Variables } & \multicolumn{1}{c}{ Categories } & $\begin{array}{c}\text { Frequency } \\
(\boldsymbol{f})\end{array}$ & $\begin{array}{c}\text { Percentage } \\
(\boldsymbol{\%})\end{array}$ \\
\hline 1 & Gender & \multicolumn{1}{c}{ Female } & 154 & 100 \\
2 & Age & 21-30 Years & 81 & 52.6 \\
& & 31-40 Years & 47 & 30.5 \\
& & $41-50$ Years & 17 & 11.0 \\
3 & \multirow{2}{*}{ Education level } & Above 50 Years & 9 & 5.8 \\
& & Diploma in General Nursing & 100 & 64.9 \\
4 & Work area & currently & 54 & 35.1 \\
& employed & Specialization & 125 & 81.2 \\
& & Greater than 5 years & 29 & 18.8 \\
\hline
\end{tabular}


International Journal of Health, Medicine and Nursing Practice ISSN 2710-1150 (Online)



Vol. 3, Issue No. 1, pp 24- 43, 2021

Www.carijournals.org

\begin{tabular}{lllcc}
\hline 5 & Training regarding & Yes & 25 & 16.2 \\
Adverse drug reactions & No & 129 & 83.8 \\
or Pharmacovigilance & & & \\
& & &
\end{tabular}

\section{Pharmacovigilance Concept and Policies}

(Table \#02) shows the knowledge regarding pharmacovigilance concept and their policies information which express the correct and incorrect responses of study participants regarding pharmacovigilance. The $87(56.5 \%)$ out of 154 participants had a concept of pharmacovigilance and $67(43.5 \%)$ don't have. Only 46(29.9) participants know the correct definition of pharmacovigilance and 108(70.1) don't know. Most of the participants 137(89.0) don't attend workshop and conference about pharmacovigilance only 17(11.0) participants attend it. 105(68.2) participants had an incorrect answer about legal medicine law in Pakistan. Only 58(37.7) out of 154 participants knew pharmacovigilance centre in Pakistan.

Table 2: Pharmacovigilance Concept and Policies of Study Participants

\begin{tabular}{llcc}
\hline S/No. & Variables & \multicolumn{2}{c}{ Response } \\
\cline { 3 - 4 } & & $\begin{array}{c}\text { Correct } \\
\boldsymbol{f}(\boldsymbol{\%})\end{array}$ & $\begin{array}{c}\text { Incorrect } \\
(\boldsymbol{\%})\end{array}$ \\
\hline 1 & Concept of Pharmacovigilance & $87(56.5)$ & $67(43.5)$ \\
2 & Correct definition of Pharmacovigilance & $46(29.9)$ & $108(70.1)$ \\
3 & Workshop or conference about & $17(11.0)$ & $137(89.0)$ \\
& Pharmacovigilance? & & \\
4 & In Pakistan, legal provisions in medicines Act & $49(31.8)$ & $105(68.2)$ \\
5 & Pharmacovigilance center? & $58(37.7)$ & $96(62.3)$ \\
6 & In Pakistan, official standardized form & $85(55.2)$ & $69(44.8)$ \\
\hline
\end{tabular}

\section{Adverse Drug Reaction Knowledge}

(Table \#03) provide the information regarding adverse drug reaction knowledge that can be assessed from the questionnaire which consists of 5 questions. The 85(55.2\%) of study participants agree with the definition of adverse drug reaction. Most of the study participants 121(78.6\%) disagree that the DoTS system and Rawlin Thompson's System are the adverse drug reaction system. Only 71(46.1\%) participants agree about the main objective of adverse drug reaction monitoring and reporting. The 93(60.4\%) participants disagree that the Spontaneous reporting system is one of the reporting systems of adverse drug reaction. Most of the study participants $116(75.3 \%)$ disagree about Naranjo's scale of adverse drug reaction. 
International Journal of Health, Medicine and Nursing Practice ISSN 2710-1150 (Online)

Vol. 3, Issue No. 1, pp 24- 43, 2021

$\underline{\text { www.carijournals.org }}$

Table 3: Adverse Drug Reaction Knowledge of Study Participants

\begin{tabular}{llcc}
\hline S/No. & \multicolumn{1}{c}{ Variables } & \multicolumn{2}{c}{ Response } \\
\cline { 3 - 4 } & & Disagree N (\%) & Agree N (\%) \\
\hline 1 & Definition of adverse drug reaction & $69(44.8)$ & $85(55.2)$ \\
2 & DoTS system and Rawlin Thompson's System & $121(78.6)$ & $33(21.4)$ \\
3 & $\begin{array}{l}\text { The main objectives of adverse drug reaction } \\
\text { monitoring and reporting. }\end{array}$ & $83(53.9)$ & $71(46.1)$ \\
4 & Spontaneous reporting system & $93(60.4)$ & $61(39.6)$ \\
5 & Naranjo's scale & $116(75.3)$ & $38(24.7)$ \\
\hline
\end{tabular}

\section{Attitude Roles and Responsibilities}

The attitude regarding pharmacovigilance and adverse drug reaction was assessed in (Table \#04) that provides the information regarding role and responsibilities. The 99(64.3) participants disagreed with that statement "Every adverse drug reaction reported should not be analyzed". Most of the participants 101(65.6) agree that the drug that causes the reaction must be identified. Only 56(36.4) out of 154 participants agreed to developed policies and procedures for an adverse drug reaction. The 103(66.9) participants disagree that the responsibilities and interactions should not be developed. The 97(63.0) out of 154 participants disagree that adverse drug reaction programs only used for educational purpose. Most of the participants 90(58.4) agree that adverse drug reactions records should be developed, maintained and evaluated. Only 65(42.2) agree that there should not organizational dissemination. The 95(61.7) participants disagree that Serious adverse drug reaction should be reported to the Food and Drug Authority. Only 52(33.8) participants agreed that important adverse drug reaction should not be published (Table \#04).

Table 4: Attitude Roles and Responsibilities of Study Participants

\begin{tabular}{|c|c|c|c|}
\hline \multirow[t]{2}{*}{ S/No. } & \multirow[t]{2}{*}{ Variables } & \multicolumn{2}{|c|}{ Response } \\
\hline & & Disagree $f(\%)$ & Agree $f(\%)$ \\
\hline 1 & $\begin{array}{l}\text { Every adverse drug reaction reported should not } \\
\text { be analyzed? }\end{array}$ & $99(64.3)$ & $55(35.7)$ \\
\hline 2 & $\begin{array}{l}\text { Patients and drugs at a high risk of being involved } \\
\text { in adverse drug reaction should be identified? }\end{array}$ & $53(34.4)$ & $101(65.6)$ \\
\hline 3 & $\begin{array}{l}\text { Policies and procedures be should develop for } \\
\text { adverse drug reaction monitoring and reporting } \\
\text { program? }\end{array}$ & $98(63.6)$ & $56(36.4)$ \\
\hline 4 & $\begin{array}{l}\text { The responsibilities and interactions of } \\
\text { pharmacists, physicians, nurses, risk managers } \\
\text { and other health professionals should not be } \\
\text { described and defined in the adverse drug reaction } \\
\text { program? }\end{array}$ & $103(66.9)$ & $51(33.1)$ \\
\hline 5 & $\begin{array}{l}\text { Adverse drug reaction programs should be used } \\
\text { for educational purpose. }\end{array}$ & $97(63.0)$ & $57(37.0)$ \\
\hline
\end{tabular}


International Journal of Health, Medicine and Nursing Practice ISSN 2710-1150 (Online)

Vol. 3, Issue No. 1, pp 24- 43, 2021

WwW.carijournals.org

\begin{tabular}{lllll}
\hline 6 & $\begin{array}{l}\text { Adverse drug reaction records should be } \\
\text { developed, maintained and evaluated }\end{array}$ & $64(41.6)$ & $90(58.4)$ \\
7 & $\begin{array}{l}\text { There should not be organizational dissemination } \\
\text { and use of information obtained through the }\end{array}$ & $89(57.8)$ & $65(42,2)$ \\
adverse drug reaction program. & & $59(38.3)$ \\
8 & $\begin{array}{l}\text { Serious adverse drug reaction should be reported } \\
\text { to the Food and drug administration or the }\end{array}$ & $95(61.7)$ & $52(33.8)$ \\
Manufacturer (or both). & $\begin{array}{l}\text { Important adverse drug reaction should not be } \\
\text { published and presented to the medical } \\
\text { community }\end{array}$ & 102(66.2) & \\
\hline
\end{tabular}

\section{Practices toward Adverse Drug Reactions Reporting Procedures}

The practices of adverse drug reaction reporting and procedures. The 101(65.6) of the study participants revealed that adverse drug reaction was identified in patients. Most of the study participants 102(66.2) have not reported an adverse drug reaction. Only 58(37.7) participants' know the exact period of reporting adverse drug reaction. The 104(67.5) out of 154 knows that where they get adverse drug reaction form. The 100(64.9) participants incorrectly answered the number of identified adverse drug reaction. Only 49(31.8) participants correctly answered that How often do patients report you adverse drug reaction. Most of the participants 95(61.7) don't know the monitoring method. The 105(68.2) participants know the monitoring method of their hospital. The 45(29.2) out of 154 participants don't know whom they report serious adverse drug reaction (Table \#05).

Table 5: Practices toward Adverse Drug Reactions Reporting Procedures of Study Participants

\begin{tabular}{|c|c|c|c|}
\hline \multirow[t]{2}{*}{ S/No. } & \multirow[t]{2}{*}{ Variables } & \multicolumn{2}{|c|}{ Response } \\
\hline & & $\begin{array}{c}\text { Correct } \\
f(\%)\end{array}$ & $\begin{array}{c}\text { Incorrect } \\
f(\%)\end{array}$ \\
\hline 1 & $\begin{array}{l}\text { Identified an adverse drug reaction in } \\
\text { patients? }\end{array}$ & $101(65.6)$ & $53(34.4)$ \\
\hline 2 & Reported an adverse drug reaction & $52(33.8)$ & $102(66.2)$ \\
\hline 3 & $\begin{array}{l}\text { Period within you should report a serious } \\
\text { adverse drug reaction }\end{array}$ & $58(37.7)$ & $96(62.3)$ \\
\hline 4 & $\begin{array}{l}\text { Where can you get the adverse drug } \\
\text { reaction reporting form? }\end{array}$ & $104(67.5)$ & $50(32.5)$ \\
\hline 5 & $\begin{array}{l}\text { The number of identified adverse drug } \\
\text { reaction in patients? }\end{array}$ & $54(35.1)$ & $100(64.9)$ \\
\hline 6 & $\begin{array}{l}\text { How often do patients report you adverse } \\
\text { drug reaction? }\end{array}$ & $49(31.8)$ & $105(68.2)$ \\
\hline 7 & $\begin{array}{l}\text { How do you prefer to report the adverse } \\
\text { drug reaction? }\end{array}$ & $109(70.8)$ & $45(29.2)$ \\
\hline 8 & Monitoring methods do you use? & $59(38.3)$ & $95(61.7)$ \\
\hline
\end{tabular}


International Journal of Health, Medicine and Nursing Practice ISSN 2710-1150 (Online)

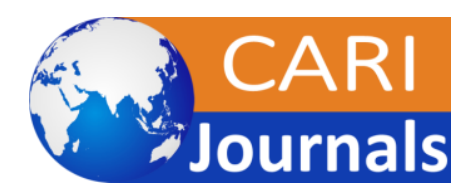

Vol. 3, Issue No. 1, pp 24- 43, 2021

Www.carijournals.org

\begin{tabular}{llll}
\hline 9 & $\begin{array}{l}\text { Adverse drug reaction monitoring in your } \\
\text { hospital/pharmacy. }\end{array}$ & $105(68.2)$ & $49(31.8)$ \\
10 & $\begin{array}{l}\text { Adverse drug reaction should be reported to } \\
\text { whom? }\end{array}$ & $109(70.8)$ & $45(29.2)$ \\
\hline
\end{tabular}

\section{Correlation of Knowledge with Attitude}

The correlation between knowledge and attitude provides in (Table \#06) which express that there was a significant relationship between knowledge and attitude of adverse drug reaction.

Table 6: Correlation of Knowledge with Attitude Items

\begin{tabular}{llcc}
\hline & & Knowledge type & Attitude type \\
\hline Knowledge & Pearson Correlation & 1 & $.164^{*}$ \\
type & Sig. (2-tailed) & & .042 \\
& $\mathrm{~N}$ & 154 & 154 \\
Attitude type & Pearson Correlation & $.164^{*}$ & 1 \\
& Sig. (2-tailed) & .042 & \\
& $\mathrm{~N}$ & 154 & 154 \\
\hline
\end{tabular}

\section{Correlation of Knowledge with Practice}

(Table \#07) provides the information regarding the correlation of knowledge and practice of adverse drug reaction which shows that there was a significant relationship between knowledge and practice of adverse drug reaction.

Table 7: Correlation of Knowledge with Practice Items

\begin{tabular}{llcc}
\hline & & Knowledge type & Practice type \\
\hline Knowledge & Pearson Correlation & 1 & $-.161^{*}$ \\
type & Sig. (2-tailed) & & .046 \\
& $\mathrm{~N}$ & 154 & 154 \\
Practice type & Pearson Correlation & $-.161^{*}$ & 1 \\
& Sig. (2-tailed) & .046 & \\
& $\mathrm{~N}$ & 154 & 154 \\
\hline
\end{tabular}

\section{DISCUSSION, CONCLUSION AND RECOMMENDATIONS}

\section{Discussion of the findings}

The study was conducted to assess nurses' knowledge, attitude, and practices in reporting and monitoring drug adverse reactions in tertiary care hospital. The pharmacovigilance and adverse drug reaction related knowledge questioners, the score less than mean of knowledge questioners considered as poor knowledge and the score more than mean of knowledge questioners considered as good knowledge. About 64.3 participants answered incorrectly which shows the poor knowledge of nurses regarding pharmacovigilance and adverse drug reaction. This finding shows that the study participants had also poor knowledge about adverse drug reaction monitoring and reporting 
International Journal of Health, Medicine and Nursing Practice ISSN 2710-1150 (Online)

Vol. 3, Issue No. 1, pp 24- 43, 2021

$\underline{\text { www.carijournals.org }}$

The current study found that most nurses have little knowledge, negative attitudes and poor practice of monitoring and reporting adverse drug reactions. Most of the study participants 85(55.2) had a concept that there is an official standardized form in Pakistan. The overall responses show that study participants had poor knowledge about the concept and policies of pharmacovigilance. An impotant finding of the present study was a positive correlation between knowledge and attitudes toward reporting adverse drug reactions. Thus, if the information on drug adverse reporting is improved, the attitude of nurses is also improved, which is reflected in the negative drug reaction reporting schemes. On the contrary, Hanafi, etc. Reported poor level of knowledge among nurses and positive attitude towards pharmaceuticals (Hanafi et al., 2012).

When participants were asked about the concept of pharmacovigilance, most participants were aware of pharmacovigilance, $56 \%$ and $96 \%$ were unaware of the pharmacovigilance center in Pakistan. A study of physicians, nurses and pharmacists in tertiary care hospital in India resulted that $62.4 \%$ of the healthcare workers positively responded to the concept of pharmacovigilance and $75.2 \%$ of health professionals were known the presence of India's National Pharmacovigilance System (Gupta, Nayak, Shivaranjani, \& Vidyarthi, 2015). Similarly, when examining the awareness of pharmacovigilance about healthcare professionals, the mean of $69.13 \%$ of nursing and $70.14 \%$ of medical professionals gave the correct answer about the concept of pharmacovigilance. (Torwane et al., 2015).

Only $31.8 \%$ of the respondents in this study are aware of the legal provisions of the Medicine Act of Pakistan. Similarly, a study conducted in India found that $28.57 \%$ of health care workers, including $8.64 \%$ of nursing and $51.47 \%$ of medical professionals were aware that the Central Drugs Standard Control Organization is a regulatory body. This agency is responsible for controlling drug adverse reactions in India. (Garg et al., 2017).

Another important finding is that nurses attending training on associated adverse reactions are almost twice as likely to report than trained ones. In this study, only 16.2 nurses had training regarding adverse drug reaction program which can lead to poor knowledge. The Spanish study, which focused on identifying drug-related problems and participating in educational activities to address them, was positively associated with reporting adverse drug reactions. (Irujo et al., 2007). This may be due to the impact of training on the reporting scheme to improve the understanding of healthcare workers. Another study emphasizes that there is a strong correlation between health professionals and pharmaceutical training in reporting adverse drug reactions that has shown negative effacts can be prevented through scientific intervention. The importance of tracking and recording can be increased (Gupta et al., 2015).

Our study revealed that $58 \%$ of nurses had a negative reaction to drugs and a negative attitude towards pharmaceuticals. This is even more important than lack of knowledge because health workers can easily be taught knowledge but without a positive attitude towards pharmaceuticals, it will not be used because reporting adverse drug reactions is still Luxury will be considered more than necessity. The pharmacovigilance and adverse drug reaction related practice questioners, the score less than mean of knowledge questioners considered as wrong practice and the score more than mean of knowledge questioners considered as good practice. About $58 \%$ of participants answered incorrectly which shows the poor knowledge of nurses regarding pharmacovigilance and 
International Journal of Health, Medicine and Nursing Practice ISSN 2710-1150 (Online)

Vol. 3, Issue No. 1, pp 24- 43, 2021

$\underline{\text { www.carijournals.org }}$

adverse drug reaction. This was evidenced by a 2012 study which concluded that pharmaceuticals and nurses were not strictly enforced when it came to reporting adverse drug reactions (Rehan, Sah, \& Chopra, 2012). In contrast, in a study conducted in New Delhi, the general mood around pharmaceuticals was positive and the average report of adverse drug reactions indicated that some parts of the country had already begun to improve (Rehan, Vasudev, \& Tripathi, 2002). While this is an associated start, there is a long way to go before reaching the ideal level. Another study was done by Hajibi et a.,l Reported that nurses with previous knowledge of the Center for Negative Drug Reactions were more knowledgeable and had a positive attitude towards reporting adverse drug reactions (Hajebi, Mortazavi, Salamzadeh, \& Zian, 2010).

The pharmacovigilance and adverse drug reaction related attitude questioners, the score less than the mean of attitude questioners considered as negative attitude and the score more than mean of knowledge questioners considered as a positive attitude. About $73 \%$ of participants answered incorrectly which shows the negative attitude of nurses regarding pharmacovigilance and adverse drug reaction.

The current study found that $66.2 \%$ of study participants did not report adverse drug reactions. $62.3 \%$ of nurses are not aware of this period in a negative drug reaction report. A survey conducted in the United Arab Emirates revealed that defendants were denied weak ways to report drug reactions. Only $12.1 \%$ and 19 hospital pharmacists and doctors revealed adverse drug reactions, respectively(Said \& Hussain, 2017). Another study concluded, "Have you ever reported a drug adverse reaction at a pharmacological center" Reported no adverse reactions and $40.8 \%$ rated it as "non-availability of adverse drug reactions forms on their sites."(Bhagavathula et al., 2016).

Patient's safety is the primary responsibility of nurses by voluntarily and actively participation in the Pharmacovigilance program. They contribute to patient safety and medical ethics. In the study, about 40 nurses felt that reporting drug reactions was a professional responsibility (John et al., 2012). A similar observation was noted by a Iranian study report (Hajebi et al., 2010)

\section{Conclusion}

It has been concluded that this study shows poor knowledge, negative attitude and poor practices of nurses regarding monitoring and reporting of adverse drug reactions and pharmacovigilance. Most pharmacovigilance studies around the world have shown that nurses have a consistently poor knowledge and practice or attitude towards reporting adverse drug reactions. In Pakistan, there are more need for training on pharmacovigilance and incorporated into tertiary training curricula for nurses to allow for better understanding and implementation. However, the responsibility lies with the governing authorities to provide them with a suitably efficient platform to practice proper adverse drug reaction reporting and monitoring.

\section{Recommendation}

This study recommends pharmacovigilance training to maximize patient safety. Nurses should be constantly updated to keep their current information on low pharmacovigilance. Nurses need to incorporate pharmacovigilance into the third training curriculum for better understanding and implementation. The results of the study show the need for an intervention program among nurses focusing on the importance of reporting drug adverse reactions and reporting procedures to 
International Journal of Health, Medicine and Nursing Practice ISSN 2710-1150 (Online)

Vol. 3, Issue No. 1, pp 24- 43, 2021

$\underline{\text { www.carijournals.org }}$

encourage their active, voluntary participation in drug safety monitoring. It is strongly indicated educational campaigns, training, economic incentives, and an easy way to report can change the level of knowledge and attitude. However, it is the responsibility of the governing body to provide them proper and competent platform for the practice of reporting and monitoring drug adverse reactions.

It is also recommended that a regulatory body that is responsible for the coordination of pharmacovigilance and adverse drug reactions reporting activities in collaboration with the Ministry of Health, training institutions and other relevant stakeholders should provide educational interventions regaridng adverse drug reaction reporting to all healthcare professionals in the country. These educational interventions should also be targeting those that are from private clinics/hospitals and those at the primary care level (health centers) as well as those from retail pharmacies and drug stores because together these facilities serve the majority of patients. Training will help healthcare professionals, as well as nurses, know what they can do and how to report and they would be encouraged to report as they would be able to understand that it is also part of their role as healthcare professionals as it also contributes to patient safety. During training, the issue of communication must be emphasized and encouraged because effective communication among healthcare professionals will facilitate signal detection and reporting of adverse drug reaction cases.

Patients' awareness regarding reporting adverse drug reactions is vital to improve their knowledge and attitude towards adverse drug reaction reporting. As a way of strengthening the pharmacovigilance system and its activities on adverse drug reaction reporting in the country, the government has to ensure that there is continued support to all trained healthcare professionals in the country in terms of ensuring that reporting tools (guidelines and reporting forms) are available and easily accessible.

\section{Limitations}

The limitation of the study is that it was done in one region of Lahore, and could not be generalized to the whole population of dispensing healthcare professionals in Lahore. The study results would have been more generalizable if the study was done in more than one region and if it had included a qualitative approach (in-depth interviews) to get a wider and in-depth understanding of respondents' knowledge, attitude and practice towards adverse drug reaction reporting. Other studies could be done to assess the knowledge and attitude of consumers towards adverse drug reaction reporting to the healthcare professionals at a national level and also studies could be done to identify the determinants of adverse drug reaction reporting.

\section{Acknowledgement}

With the name of Allah, the most Beneficent and Merciful. All respects to our last Prophet Hazrat Muhammad (S.A.W) who teaches us the ways of learning, knowledge and wisdom for all humanity.

I would like to mention my support system and consideration of my parents who have always been there in my life. I am also thanks to my advisor Mr. Muhammad Hussain for their friendly approach and support from proposal development till final result. I am very grateful to the head of 
International Journal of Health, Medicine and Nursing Practice ISSN 2710-1150 (Online)

Vol. 3, Issue No. 1, pp 24- 43, 2021

$\underline{\text { www.carijournals.org }}$

department Mr. Muhammad Afzal, Lahore School of Nursing, who provide me opportunity to conduct research on my interest and the University of Lahore for providing me valuable suggestion, persistent inspiration and continuous supervision to complete this research.

Finally, my deepest gratitude also goes to all study participants for their commitment during data collection.

\section{Author Contribution}

The first author contributing to knowledge analysis, drafting the article and gave final approval of the version.

\section{Finding Source}

The author did not receive any specific grant from any funding agencies.

\section{Availability of Data and Material}

A questionnaire guide is available from the corresponding author upon reasonable request.

\section{REFERENCES}

Adenuga, B. A., Kibuule, D., Rennie, T. W. J. B., pharmacology, c., \& toxicology. (2020). Optimizing spontaneous adverse drug reaction reporting in public healthcare setting in Namibia. 126(3), 247-253.

Adisa, R., \& Omitogun, T. I. J. B. h. s. r. (2019). Awareness, knowledge, attitude and practice of adverse drug reaction reporting among health workers and patients in selected primary healthcare centres in Ibadan, southwestern Nigeria. 19(1), 1-14.

Almandil, N. B. J. S. m. j. (2016). Healthcare professionals' awareness and knowledge of adverse drug reactions and pharmacovigilance. 37(12), 1359.

Atif, M., Malik, I., Asif, M., Qamar-Uz-Zaman, M., Ahmad, N., \& Scahill, S. (2020). Drug safety in Pakistan Drug Safety in Developing Countries (pp. 287-325): Elsevier.

Bhagavathula, A. S., Elnour, A. A., Jamshed, S. Q., \& Shehab, A. J. P. o. (2016). Health professionals' knowledge, attitudes and practices about pharmacovigilance in India: A systematic review and meta-analysis. 11(3), e0152221.

Bigi, C., \& Bocci, G. J. E. j. o. c. p. (2017). The key role of clinical and community health nurses in pharmacovigilance. 73(11), 1379-1387.

BR, A., \& Kar, S. (2020). Knowledge, attitude and practices of postgraduates, interns and nurses, on adverse drug reaction reporting in a tertiary care hospital: a comparative study.

Coleman, J. J., \& Pontefract, S. K. (2016). Adverse drug reactions. Clinical Medicine, 16(5), 481.

De Angelis, A., Giusti, A., Colaceci, S., Vellone, E., \& Alvaro, R. J. A. d. I. s. d. s. (2015). Nurses' reporting of suspect adverse drug reactions: a mixed-methods study. 51, 277-283. 
International Journal of Health, Medicine and Nursing Practice ISSN 2710-1150 (Online)

Vol. 3, Issue No. 1, pp 24- 43, 2021

$\underline{\text { www.carijournals.org }}$

Elhassan, G. O. J. J. o. P. (2015). Pharmacovigilance: clinical perspectives towards patient safety.

Ferner, R., \& Aronson, J. J. B. j. o. c. p. (2019). Susceptibility to adverse drug reactions. 85(10), 2205-2212.

Garg, P., Sharma, V., \& Bajaj, J. (2017). Assessment of knowledge, attitude and practice of Pharmacovigilance among the interns in a tertiary care hospital in northern India-A questionnaire based study.

Gupta, S. K., Nayak, R. P., Shivaranjani, R., \& Vidyarthi, S. K. J. P. i. c. r. (2015). A questionnaire study on the knowledge, attitude, and the practice of pharmacovigilance among the healthcare professionals in a teaching hospital in South India. 6(1), 45.

Hajebi, G., Mortazavi, S. A., Salamzadeh, J., \& Zian, A. J. I. j. o. p. r. I. (2010). A survey of knowledge, attitude and practice of nurses towards pharamacovigilance in Taleqani hospital. 9(2), 199.

Hanafi, S., Torkamandi, H., Hayatshahi, A., Gholami, K., Javadi, M. J. I. j. o. n., \& research, m. (2012). Knowledge, attitudes and practice of nurse regarding adverse drug reaction reporting. $17(1), 21$.

Hussain, R., Hassali, M. A., Hashmi, F., Farooqui, M. J. J. o. p. p., \& practice. (2018). A qualitative exploration of knowledge, attitudes and practices of hospital pharmacists towards adverse drug reaction reporting system in Lahore, Pakistan. 11(1), 1-10.

Irujo, M., Beitia, G., Bes-Rastrollo, M., Figueiras, A., Hernandez-Diaz, S., \& Lasheras, B. J. D. s. (2007). Factors that influence under-reporting of suspected adverse drug reactions among community pharmacists in a Spanish region. 30(11), 1073-1082.

John, L. J., Arifulla, M., Cheriathu, J. J., \& Sreedharan, J. J. D. J. o. P. S. (2012). Reporting of adverse drug reactions: an exploratory study among nurses in a teaching hospital, Ajman, United Arab Emirates. 20(1), 1-6.

Jordan, S., Gabe-Walters, M. E., Watkins, A., Humphreys, I., Newson, L., Snelgrove, S., \& Dennis, M. S. J. P. O. (2015). Nurse-Led medicines' monitoring for patients with dementia in care homes: a pragmatic cohort stepped wedge cluster randomised trial. 10(10), e0140203.

Jordan, S., Vaismoradi, M., \& Griffiths, P. (2016). Adverse Drug Reactions, Nursing and Policy: A NarrativeReview.

Khalil, H., \& Huang, C. J. B. h. s. r. (2020). Adverse drug reactions in primary care: a scoping review. 20(1), 1-13.

Khalili, M., Sharifi, H., Mesgarpour, B., Kheirandish, M., Olsson, S., Javidnikou, N., . . . Management. (2020). Evaluation of Pharmacovigilance System in Iran. 
International Journal of Health, Medicine and Nursing Practice ISSN 2710-1150 (Online)

Vol. 3, Issue No. 1, pp 24- 43, 2021

$\underline{\text { www.carijournals.org }}$

Kumari, A., Haque, I., Bhyan, S. J., Sreelakshmi, M., Goel, N., Jain, A., . . Chauhan, R. (2020). Knowledge, Attitude and Practice of Adverse Drug Reaction Monitoring and Pharmacovigilance among Various Healthcare Professionals in India.

Napuce, A., \& Tabaku, A. (2019). Health Care Workers'knowleddge And Perceptions About Pharmacovigilance And Adverse Drug Reactions Reporting.

Nasir, M., Zahan, T., Farha, N., Chowdhury, A. S. J. I. J. o. B., \& Pharmacology, C. (2020). Acquaintance, approach and application of pharmacovigilance: questionnaire based study at a tertiary care teaching hospital in Dhaka. 9(10), 1497.

Nisa, Z. U., Zafar, A., \& Sher, F. J. S. P. J. (2018). Assessment of knowledge, attitude and practice of adverse drug reaction reporting among healthcare professionals in secondary and tertiary hospitals in the capital of Pakistan. 26(4), 453-461.

O’Callaghan, J., Griffin, B. T., Morris, J. M., \& Bermingham, M. (2018). Knowledge of adverse drug reaction reporting and the pharmacovigilance of biological medicines: a survey of healthcare professionals in Ireland. BioDrugs, 32(3), 267-280.

Peabody, J., Acelajado, M. C., Robert, T., Hild, C., Schrecker, J., Paculdo, D., . . Jeter, E. J. J. o. c. m. r. (2018). Drug-drug interaction assessment and identification in the primary care setting. 10(11), 806.

Rehan, H., Sah, R. K., \& Chopra, D. J. I. j. o. p. (2012). Comparison of knowledge, attitude and practices of resident doctors and nurses on adverse drug reaction monitoring and reporting in a tertiary care hospital. 44(6), 699.

Rehan, H., Vasudev, K., \& Tripathi, C. (2002). Adverse drug reaction monitoring: knowledge, attitude and practices of medical students and prescribers. National Medical Journal of India, 15(1), 24-26.

RM, V., Kalpana, L., \& CR, M. (2021). Knowledge, Attitude and Practice of Pharmacovigilance Among Nursing Staff in BGS GIMS Hospital. Biomedical and Pharmacology Journal, $14(1)$.

Said, A. S., \& Hussain, N. J. H. p. (2017). Adverse drug reaction reporting practices among United Arab Emirates pharmacists and prescribers. 52(5), 361-366.

Sen, S., Rahaman, S. R., Chatterjee, D., Mukherjee, S., Mondal, S., \& Tripathi, S. (2017). Knowledge, attitudes and practice of adverse drug reaction monitoring among physicians in India. Ijbcp, 6, 1497-1506.

Torwane, N. A., Hongal, S., Gouraha, A., Saxena, E., Chavan, K. J. T. J. o. N. A. B. f. H., \& Providers, H. (2015). Awareness related to reporting of adverse drug reactions among health caregivers: A cross-sectional questionnaire survey. 2(1), 23.

Zaman, S. U., Ramesh, L., Priya, B. V., Beedimani, R. S., Manikanta, M. J. N. J. o. P., Pharmacy, \& Pharmacology. (2021). Adverse drug reactions: An analysis of spontaneous reports. 11(2), 141-146. 
International Journal of Health, Medicine and Nursing Practice

ISSN 2710-1150 (Online)



Vol. 3, Issue No. 1, pp 24- 43, 2021

Www.carijournals.org 